\title{
COVID-19 and its Cardiac and Neurological Complications among Ontario Visible Minorities
}

\author{
Joseph Y. Chu (D), Yosuf Kaliwal, Maria Koh, Robert Chen, Chi-Ming Chow, \\ Dennis T. Ko, Peter P. Liu, Gordon W. Moe
}

\begin{abstract}
Background: Due to lack of data on the epidemiology, cardiac, and neurological complications among Ontario visible minorities (Chinese and South Asians) affected by coronavirus disease (COVID-19), this population-based retrospective study was undertaken to study them systematically. Methods: From January 1, 2020 to September 30, 2020 using the last name algorithm to identify Ontario Chinese and South Asians who were tested positive by PCR for COVID-19, their demographics, cardiac, and neurological complications including hospitalization and emergency visit rates were analyzed compared to the general population. Results: Chinese $(\mathrm{N}=1,186)$ with COVID-19 were found to be older (mean age 50.7 years) compared to the general population $(\mathrm{N}=42,547)$ (mean age 47.6 years) $(p<0.001)$, while South Asians $(\mathrm{N}=3,459)$ were younger (age of 42.1 years) $(p<0.001)$. The 30 -day crude rate for cardiac complications among Chinese was 169/10,000 $(p=0.069)$, while for South Asians, it was 64/10,000 $(p=0.008)$ and, for the general population, it was $112 / 10,000$. For neurological complications, the 30-day crude rate for Chinese was 160/10,000 $(p<0.001)$; South Asians was 40/10,000 $(p=0.526)$, and general population was 48/10,000. The 30-day all-cause mortality rate was significantly higher for Chinese at $8.1 \%$ vs $5.0 \%$ for the general population $(p<0.001)$, while it was lower in South Asians at $2.1 \%(p<0.001)$. Conclusions: Chinese and South Asians in Ontario affected by COVID-19 during the first wave of the pandemic were found to have a significant difference in their demographics, cardiac, and neurological outcomes.
\end{abstract}

RÉSUMÉ : Les complications cardiaques et neurologiques liées aux infections à la COVID-19 parmi des minorités visibles en Ontario. Contexte : C'est en raison d'un manque de données portant sur l'épidémiologie ainsi que sur les complications cardiaques et neurologiques des minorités visibles de l'Ontario (de descendance chinoise ou sud-asiatique) atteintes par une infection à la COVID-19 que cette étude rétrospective basée sur la population a été entreprise en vue d'étudier cette réalité de façon systématique. Méthodes : C'est au moyen d'un algorithme des noms de famille que nous avons pu identifier des Ontariens de descendance chinoise ou sud-asiatique qui ont obtenu un résultat positif à un test PCR (polymerase chain reaction) de dépistage de la COVID-19, et ce, du $1^{\mathrm{er}}$ janvier au 30 septembre 2020. Nous avons ensuite procédé à une analyse de leurs caractéristiques démographiques et de leurs complications cardiaques et neurologiques, ce qui inclut les taux d'hospitalisation et de visite à un service d'urgence, en comparaison avec la population générale. Résultats : Les individus de descendance chinoise $(n=1186)$ atteints de COVID-19 se sont révélés plus âgés (âge moyen $=50,7$ ans) si on les compare à la population générale $(n=42547$; âge moyen $=47,6$ ans ; $p<0,001)$ tandis que ceux de descendance sud-asiatique $(n=3459)$ étaient plus jeunes (âge moyen $=42,1$ ans; $p<0,001$ ). Le taux brut de complications cardiaques au bout de 30 jours parmi les Ontariens de descendance chinoise était de 169/10 $000(p=0,069)$ alors qu'il était de 64/10 $000(p=0,008)$ chez les Ontariens de descendance sud-asiatique et de $112 / 10000$ au sein de la population générale. En ce qui concerne les complications neurologiques, le taux brut de complications au bout de 30 jours était de $160 / 10000$ ( $p<0,001$ ) chez les Ontariens de descendance chinoise, de 40/10 $000(p=0,526)$ chez ceux de descendance sud-asiatique et de 48/10 000 au sein de la population générale. Enfin, soulignons que le taux de mortalité (toutes causes confondues) au bout de 30 jours était notablement plus élevé chez les Ontariens de descendance chinoise $(8,1 \%)$ en comparaison avec la population générale $(5,0 \% ; p<0,001)$ alors qu'il s'est avéré inférieur chez les Ontariens de descendance sud-asiatique $(2,1 \% ; p<0,001)$. Conclusions : En somme, les Ontariens de descendance chinoise ou sud-asiatique touchés par une infection à la COVID-19 lors de la première vague de la pandémie ont présenté des différences significatives en ce qui regarde leurs caractéristiques démographiques et les conséquences de cette infection d'un point de vue cardiaque et d'un point de vue neurologique.

Keywords: COVID-19, Cardiac complications, Neurological complications, Chinese and South Asians, Clinical epidemiology doi:10.1017/cjn.2021.148

Can J Neurol Sci. 2022; 49: 504-513

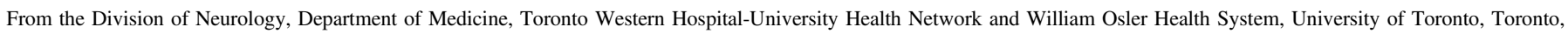

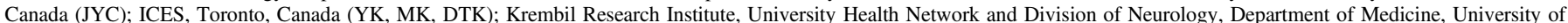

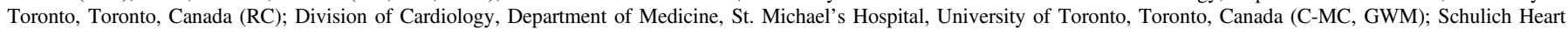

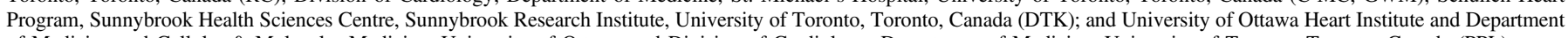
of Medicine and Cellular \& Molecular Medicine, University of Ottawa and Division of Cardiology, Department of Medicine, University of Toronto, Toronto, Canada (PPL)

Received June 17, 2021. Date of Acceptance June 19, 2021.

Correspondence to: Joseph Y. Chu, Queensway Professional Centre, 312-190 Sherway Drive, Toronto, Ontario, Canada M9C 5N2. Email: jychu@rogers.com 


\section{INTRODUCTION}

Severe acute respiratory syndrome coronavirus 2 (SARS$\mathrm{CoV}-2$ ) is responsible for the global pandemic now known as coronavirus disease (COVID-19). ${ }^{1,2}$ Data from outside Canada suggest that there are substantial disparities among different ethnic groups in who gets infected and who have adverse outcomes. ${ }^{14,17,18,28,29}$ In the USA, according to a report by Center for Disease Control in 2020, ${ }^{13} 33 \%$ of hospitalized patients were black, compared to $18 \%$ in the community, and $8 \%$ were Hispanic, compared to $14 \%$ in the community. The overall mortality rates among African Americans were much higher than that of the white and Asian persons. ${ }^{13}$ However, the racial distribution in the impact of COVID-19 in Canada has not been studied systematically. ${ }^{2,10,19}$ In Ontario and based on the 2016 Canadian census, Chinese accounts for $19.4 \%$, while South Asians accounts for $29.6 \%$ of visible minorities. ${ }^{42}$ Therefore, these two ethnic groups account for almost $50 \%$ of visible minorities in Ontario. Despite the collected data on COVID-19 in the general population of Ontario, ${ }^{1}$ however there is a paucity of information on how these two minority ethnic groups are affected by COVID-19, in particular their rates and types of cardiac and neurological complications. Accordingly, we conducted a population-based retrospective study to evaluate the epidemiology as well as potential cardiac ${ }^{31,33,34}$ and neurological complications $^{4,5,43,44}$ of COVID-19 among Chinese and South Asians compared to the general population in Ontario.

\section{Methods}

\section{Data Sources}

To identify the cohort, we used the Ontario Laboratory Information System database and selected those who had a positive COVID test result between January 1, 2020 and September 30, 2020 inclusive. To identify baseline demographics and health conditions, health outcomes, and health service use, we used data from the Registered Persons Database (RPDB), Canadian Institute for Health Information (CIHI) Discharge Abstract Database (DAD), the National Ambulatory Care Reporting System (NACRS), and the Ontario Health Insurance Plan (OHIP) physician claims database. The RPDB provides basic demographic information about anyone who has ever received an Ontario health card number. The DAD contains patient-level data for hospitalizations. The NACRS captures information on patient visits to emergency departments. OHIP captures information of the services provided by practicing physicians in Ontario. These data sets were linked using unique encoded identifiers and analyzed at ICES.

\section{Study Population}

The cohort included individuals between the ages of 18 and 105, who had a positive COVID-19 test between January 1, 2020 and September 30, 2020. We excluded patients who were not Ontario residents at the time of the COVID-19 test. If the person had multiple positive tests within the study period, the first positive test date was chosen as the index date. Individuals' ethnicities (classified into Chinese, South Asian, and all others hereby termed General) were determined using an algorithm developed by Shah et al. which uses a surname-based approach to identify ethnicity based on an individuals' surname. ${ }^{40}$ The use of the data in this project is authorized under section 45 of Ontario's Personal Health Information Protection Act (PHIPA) and does not require review by a Research Ethics Board.

\section{Outcomes}

The primary outcome of interest was death. Cardiac outcome including myocardial infarction, heart failure, arrhythmia, atrial fibrillation and flutter, myocarditis, deep vein thrombosis/ pulmonary embolism (DVT/PE). Neurological outcomes include hemorrhagic stroke, ischemic stroke, seizure, meningitis, encephalitis, encephalopathy, and Parkinson's disease. Health service use includes hospitalization, emergency room visit, intensive care units (ICU) admission, use of extracorporeal membrane oxygenation, and use of mechanical ventilation within 30 days of having a positive COVID-19 test (Codes are listed in Appendix A). The outcomes were measured at the individual level indicating whether the patient did or did not experience the outcome.

\section{Statistical Analysis}

Baseline and outcome characteristics were compared between the Chinese and South Asians versus the general population. In addition, Charlson comorbidity index and 30-day all-cause mortality rate, cardiac and neurological complication rates were also analyzed. For continuous variables, descriptive statistics included mean values with standard deviation, median values with interquartile range, and the $p$-values were calculated using one-way analysis of variance for means and Kruskal-Wallis test for medians. Categorical variables were described using proportions, and $p$-values from a chi-squared test were provided. $p$-Values were used to compare the Chinese population to the general population and to compare the South Asians population to the general population. Multivariable logistic regression was used to determine if ethnicity was associated with death, cardiac outcomes, neurological outcomes, or hospitalization or emergency department visits. A separate logistic regression model was built for each binary outcome with ethnicity as the main exposure categorical variable and the general population as the reference group. Adjustment variables included age, sex, income quintile which is defined as the quintile of neighborhood income per person equivalent within a census metropolitan area, census agglomeration or residual area (Table 1), and long-term care placement within 90 days (Table 2) prior to positive COVID test. Odds ratios (ORs) comparing Chinese and South Asian ethnicities to the general population were computed for each outcome.

\section{Results}

Chinese $(\mathrm{N}=1,186)$ infected by COVID-19 were older with a mean age of 50.7 years compared to general population $(\mathrm{N}=42,547)$ of 47.6 years $(p<0.001)$, while South Asians $(\mathrm{N}=3.459)$ were younger with a mean age of 42.1 years $(p<0.001) .14 .0 \%$ of Chinese and only $3.8 \%$ of South Asians were $>80$ years compared to $12.4 \%$ of the general population (Table 1). There was no statistical difference in sex distribution for Chinese, while for South Asians $53.9 \%$ were male compared to $46.4 \%$ in the general population $(p<0.001)$. Income quintile showed that only $8.2 \%$ of South Asians were in the highest category (quintile 5), while for general population, it was $14.6 \%$. The majority of both Chinese and South Asians (99.2\% and 
Table 1: Baseline characteristics of patients by ethnic group

\begin{tabular}{|c|c|c|c|c|c|c|}
\hline & Chinese & South Asian & General & Overall & $p$-Values & $p$-Values \\
\hline Characteristics & $\mathrm{N}=1,186$ & $\mathrm{~N}=\mathbf{3 , 4 5 9}$ & $\mathrm{N}=\mathbf{4 2 , 5 4 7}$ & $\mathrm{N}=47,192$ & Chinese vs General & $\begin{array}{c}\text { South Asian vs } \\
\text { General }\end{array}$ \\
\hline Age, mean (SD) & $50.7 \pm 21.9$ & $42.1 \pm 19.2$ & $47.6 \pm 23.0$ & $47.3 \pm 22.8$ & $<.001$ & $<.001$ \\
\hline Age, median (IQR) & $51(32-64)$ & $40(27-56)$ & $46(28-63)$ & $46(28-62)$ & $<.001$ & $<.001$ \\
\hline Age groups & & & & & $<.001$ & $<.001$ \\
\hline 19 and under & $58(4.9 \%)$ & $320(9.3 \%)$ & $3,737(8.8 \%)$ & $4,115(8.7 \%)$ & & \\
\hline 20 to 39 & $355(29.9 \%)$ & $1,402(40.5 \%)$ & $13,830(32.5 \%)$ & $15,587(33.0 \%)$ & & \\
\hline 40 to 59 & $403(34.0 \%)$ & $1,059(30.6 \%)$ & $12,479(29.3 \%)$ & $13,941(29.5 \%)$ & & \\
\hline 60 to 79 & $204(17.2 \%)$ & $546(15.8 \%)$ & $7,208(16.9 \%)$ & $7,958(16.9 \%)$ & & \\
\hline $80+$ & $166(14.0 \%)$ & $132(3.8 \%)$ & $5,293(12.4 \%)$ & $5,591(11.8 \%)$ & & \\
\hline Sex & & & & & 0.808 & $<.001$ \\
\hline Male & $546(46.0 \%)$ & $1,865(53.9 \%)$ & $19,739(46.4 \%)$ & $22,150(46.9 \%)$ & & \\
\hline Female & $640(54.0 \%)$ & $1,594(46.1 \%)$ & $22,808(53.6 \%)$ & $25,042(53.1 \%)$ & & \\
\hline Income Quintile & & & & & 0.365 & $<.001$ \\
\hline $\begin{array}{l}\text { Income Quintile } 1 \\
\text { (lowest) }\end{array}$ & $335(28.2 \%)$ & $659(19.1 \%)$ & $12,066(28.4 \%)$ & $13,060(27.7 \%)$ & & \\
\hline Income Quintile 2 & $268(22.6 \%)$ & $935(27.0 \%)$ & $8,990(21.1 \%)$ & $10,193(21.6 \%)$ & & \\
\hline Income Quintile 3 & $205(17.3 \%)$ & $1,012(29.3 \%)$ & $8,340(19.6 \%)$ & $9,557(20.3 \%)$ & & \\
\hline Income Quintile 4 & $194(16.4 \%)$ & $560(16.2 \%)$ & $6,778(15.9 \%)$ & $7,532(16.0 \%)$ & & \\
\hline $\begin{array}{l}\text { Income Quintile } 5 \\
\text { (highest) }\end{array}$ & $181(15.3 \%)$ & $284(8.2 \%)$ & $6,205(14.6 \%)$ & $6,670(14.1 \%)$ & & \\
\hline Residence & & & & & $<.001$ & $<.001$ \\
\hline Rural & $6(0.5 \%)$ & $15(0.4 \%)$ & $1,528(3.6 \%)$ & $1,549(3.3 \%)$ & & \\
\hline Urban & $1,177(99.2 \%)$ & $3,435(99.3 \%)$ & $40,867(96.1 \%)$ & $45,479(96.4 \%)$ & & \\
\hline
\end{tabular}

Table 2: Baseline characteristics of patients by ethnic group: comorbidities, long-term care status, and hospitalization

\begin{tabular}{|c|c|c|c|c|c|c|}
\hline \multirow[b]{2}{*}{ Characteristics } & Chinese & South Asian & General & Overall & $p$-Values & $p$-Values \\
\hline & $\mathrm{N}=1,186$ & $\mathrm{~N}=\mathbf{3 , 4 5 9}$ & $\mathrm{N}=42,547$ & $\mathrm{~N}=47,192$ & Chinese vs General & $\begin{array}{c}\text { South Asian vs } \\
\text { General }\end{array}$ \\
\hline Asthma & $135(11.4 \%)$ & $542(15.7 \%)$ & $6,823(16.0 \%)$ & $7,500(15.9 \%)$ & $<.001$ & 0.571 \\
\hline Diabetes & $209(17.6 \%)$ & $683(19.7 \%)$ & $7,302(17.2 \%)$ & $8,194(17.4 \%)$ & 0.679 & $<.001$ \\
\hline Hypertension & $389(32.8 \%)$ & $884(25.6 \%)$ & $12,987(30.5 \%)$ & $14,260(30.2 \%)$ & 0.093 & $<.001$ \\
\hline Heart failure & $40(3.4 \%)$ & $93(2.7 \%)$ & $2,243(5.3 \%)$ & $2,376(5.0 \%)$ & 0.004 & $<.001$ \\
\hline COPD & $23(1.9 \%)$ & $43(1.2 \%)$ & $1,521(3.6 \%)$ & $1,587(3.4 \%)$ & 0.003 & $<.001$ \\
\hline Dementia & $140(11.8 \%)$ & $107(3.1 \%)$ & $4,881(11.5 \%)$ & $5,128(10.9 \%)$ & 0.723 & $<.001$ \\
\hline Chronic kidney disease & $55(4.6 \%)$ & $100(2.9 \%)$ & $2,159(5.1 \%)$ & $2,314(4.9 \%)$ & 0.498 & $<.001$ \\
\hline $\begin{array}{l}\text { LTC within } 90 \text { days } \\
\text { from testing date }\end{array}$ & $162(13.7 \%)$ & $110(3.2 \%)$ & $5,207(12.2 \%)$ & $5,479(11.6 \%)$ & 0.141 & $<.001$ \\
\hline $\begin{array}{l}\text { LTC status on testing } \\
\text { date }\end{array}$ & $76(6.4 \%)$ & $48(1.4 \%)$ & $2,136(5.0 \%)$ & $2,260(4.8 \%)$ & 0.031 & $<.001$ \\
\hline $\begin{array}{l}\text { Hospitalization (last } 5 \\
\text { years from index) }\end{array}$ & $317(26.7 \%)$ & $696(20.1 \%)$ & $12,054(28.3 \%)$ & $13,067(27.7 \%)$ & 0.227 & $<.001$ \\
\hline
\end{tabular}

$\mathrm{COPD}=$ chronic obstructive pulmonary disease, $\mathrm{LTC}=$ long-term care. 
Table 3: Baseline characteristics of patients by ethnic group: Charlson comorbidity index

\begin{tabular}{|c|c|c|c|c|c|c|}
\hline \multirow[b]{2}{*}{ Characteristics } & Chinese & South Asian & General & Overall & $p$-Value & p-Value \\
\hline & $N=1,186$ & $\mathrm{~N}=\mathbf{3 , 4 5 9}$ & $N=42,547$ & $N=47,192$ & $\begin{array}{c}\text { Chinese vs } \\
\text { General }\end{array}$ & $\begin{array}{l}\text { South Asian vs } \\
\text { General }\end{array}$ \\
\hline \multicolumn{7}{|l|}{$\begin{array}{l}\text { Charlson comorbidity index (past } 5 \text { years } \\
\text { from index) }\end{array}$} \\
\hline Acute Myocardial Infarction & $14(1.2 \%)$ & $32(0.9 \%)$ & $515(1.2 \%)$ & $561(1.2 \%)$ & 0.926 & 0.137 \\
\hline Congestive Heart Failure & $27(2.3 \%)$ & $46(1.3 \%)$ & $1,123(2.6 \%)$ & $1,196(2.5 \%)$ & 0.441 & $<.001$ \\
\hline Peripheral Vascular Disease & $8(0.7 \%)$ & $8(0.2 \%)$ & $309(0.7 \%)$ & $325(0.7 \%)$ & 0.836 & $<.001$ \\
\hline Cerebrovascular Disease & $33(2.8 \%)$ & $32(0.9 \%)$ & $963(2.3 \%)$ & $1,028(2.2 \%)$ & 0.237 & $<.001$ \\
\hline Dementia & $62(5.2 \%)$ & $48(1.4 \%)$ & $2,136(5.0 \%)$ & $2,246(4.8 \%)$ & 0.747 & $<.001$ \\
\hline $\begin{array}{l}\text { Chronic Obstructive Pulmonary } \\
\text { Disease or other Respiratory } \\
\text { diseases }\end{array}$ & $12(1.0 \%)$ & $27(0.8 \%)$ & $965(2.3 \%)$ & $1,004(2.1 \%)$ & 0.004 & $<.001$ \\
\hline Rheumatic-like Diseases & $\leq 5$ & $\leq 5$ & $119(0.3 \%)$ & $124(0.3 \%)$ & 0.365 & 0.002 \\
\hline Ulcers of the Digestive System & $7(0.6 \%)$ & $11(0.3 \%)$ & $230(0.5 \%)$ & $248(0.5 \%)$ & 0.818 & 0.081 \\
\hline Liver Disease - Mild & $\leq 5$ & $\leq 5$ & $150(0.4 \%)$ & $158(0.3 \%)$ & 0.382 & 0.004 \\
\hline Diabetes - No Chronic Complications & $41(3.5 \%)$ & $73(2.1 \%)$ & $1,020(2.4 \%)$ & $1,134(2.4 \%)$ & 0.019 & 0.287 \\
\hline Diabetes with Chronic Complications & $47(4.0 \%)$ & $100(2.9 \%)$ & $1,845(4.3 \%)$ & $1,992(4.2 \%)$ & 0.533 & $<.001$ \\
\hline Hemiplegia or Paraplegia & $8(0.7 \%)$ & $13(0.4 \%)$ & $315(0.7 \%)$ & $336(0.7 \%)$ & 0.794 & 0.014 \\
\hline Renal (Kidney) Disease & $14(1.2 \%)$ & $20(0.6 \%)$ & $661(1.6 \%)$ & $695(1.5 \%)$ & 0.304 & $<.001$ \\
\hline Cancer (No secondary found) & $16(1.3 \%)$ & $26(0.8 \%)$ & $615(1.4 \%)$ & $657(1.4 \%)$ & 0.784 & $<.001$ \\
\hline Liver Disease - Moderate or Severe & $* 3-8$ & $* 3-8$ & $70(0.2 \%)$ & $80(0.2 \%)$ & 0.499 & 0.191 \\
\hline Cancer (Metastatic - secondary) & $* 8-12$ & $\leq 5$ & $166(0.4 \%)$ & $181(0.4 \%)$ & 0.004 & 0.01 \\
\hline Mean \pm SD & $0.38 \pm 1.14$ & $0.19 \pm 0.80$ & $0.37 \pm 1.11$ & $0.36 \pm 1.09$ & 0.676 & $<.001$ \\
\hline Median (IQR) & $0(0-0)$ & $0(0-0)$ & $0(0-0)$ & $0(0-0)$ & 0.918 & $<.001$ \\
\hline Charlson category & & & & & 0.995 & $<.001$ \\
\hline 0 & $1,011(85.2 \%)$ & $3,181(92.0 \%)$ & $36,290(85.3 \%)$ & $40,482(85.8 \%)$ & & \\
\hline 1 & $64(5.4 \%)$ & $113(3.3 \%)$ & $2,268(5.3 \%)$ & $2,445(5.2 \%)$ & & \\
\hline$\geq 2$ & $111(9.4 \%)$ & $165(4.8 \%)$ & $3,989(9.4 \%)$ & $4,265(9.0 \%)$ & & \\
\hline
\end{tabular}

$\mathrm{IQR}=$ interquartile range, $\mathrm{SD}=$ standard deviation.

99.3\%) and the general population (96.1\%) were from urban areas (Table 1). Among the components of the Charlson comorbidity index (past 5 years from index), for Chinese, only chronic obstructive pulmonary disease or other respiratory diseases $(1.0 \%)$ vs general population $(2.3 \%)$ were significantly different $(p=0.004)$ (Table 3). Rate of past hospitalization was similar in Chinese $(26.7 \%$ vs $28.3 \%, p=0.227)$, while it was lower among South Asians $(20.1 \%$ vs $28.3 \%, p<0.001)$ (Table 2).

The clinical outcomes for all 3 cohorts are shown in Figures 1-5. Compared to the general population, emergency visits and ICU admission rates were both higher for Chinese, while they were lower in South Asians (both $p<0.003$ ). These data were further dichotomized into $<65$ years old (Figure 1) and for those $\geq 65$ years old (Figure 2). In addition, the data were also analyzed based on those residing in long-term care facilities (Figure 3) and compared to those who were not in long-term care facilities. (Figure 4) The 30-day all-cause mortality rate was much higher for Chinese at $8.1 \%$ vs $5.0 \%$ of the general population, while it was much lower in South Asians at only $2.1 \%(p<0.001)$ (Figure 5). The overall cardiac complication rate was found to be higher for Chinese compared to the general population $(1.7 \%$ vs $1.1 \%, p=0.003)$ and especially for those 65 years and older. The overall neurological complication rate for the general population was very low $(0.5 \%)$ but was higher in Chinese $(1.6 \%, p=0.005)$ and tended to be lower in South Asians (0.4\%, $p>0.05)$ (Figure 5). Among all the neurological complications, encephalopathy was the commonest accounting for $6.4 \%$ of hospitalized and $14.1 \%$ of Chinese admitted to ICU but it was not statistically significant compared to the general population. The 30-day crude rate for cardiac complications among Chinese was 169/10,000 $(p=0.069)$ and for the general population was $112 / 10,000$. For neurological complications, the 30-day crude rate for Chinese was 160/10,000 $(p<0.001)$; general population was 48/10,000 (Figure 5).

For South Asians with COVID-19, the incidence of underlying diabetes was higher than the general population $(19.7 \%$ vs $17.2 \%, p<0.001$ ), while they were lower in the following premorbid conditions: hypertension, heart failure, chronic obstructive pulmonary disease (COPD), dementia, and chronic kidney disease $(p<0.001)$. Only $3.2 \%$ of South Asians were in 


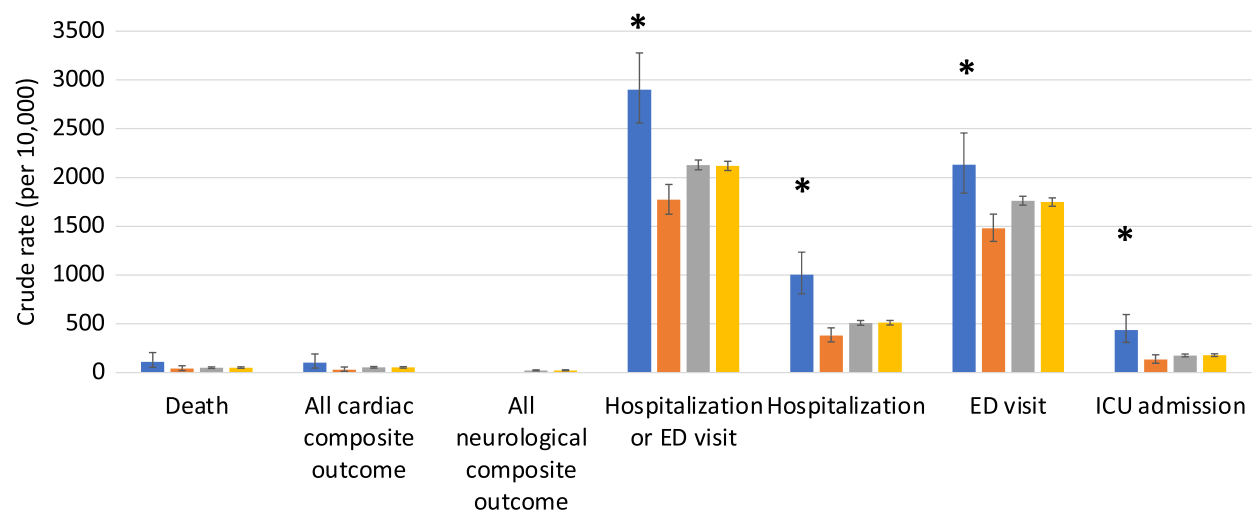

- Chinese Crude Rate $\quad$ South Asian Crude Rate $\quad$ General Crude Rate $\quad$ Overall Crude Rate Figure 1: 30-day crude rates by ethnic groups for under age 65 years. Error bars represent standard deviation. Asterisks indicate significant difference compared to the general crude rate. ED, emergency department; ICU, intensive care unit.

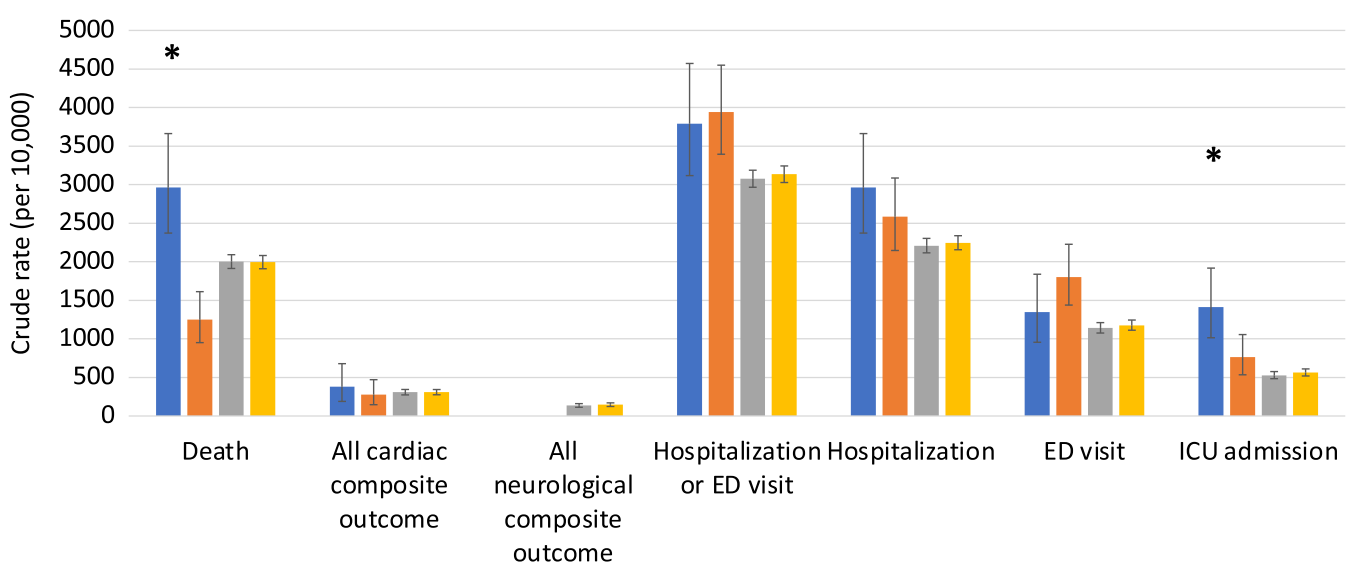

- Chinese Crude Rate $\quad$ South Asian Crude Rate General Crude Rate $\quad$ Overall Crude Rate

Figure 2: 30-day crude rates by ethnic groups for age 65 years or older. Error bars represent standard deviation. Asterisks indicate significant difference compared to the general crude rate. ED, emergency department; ICU, intensive care unit.

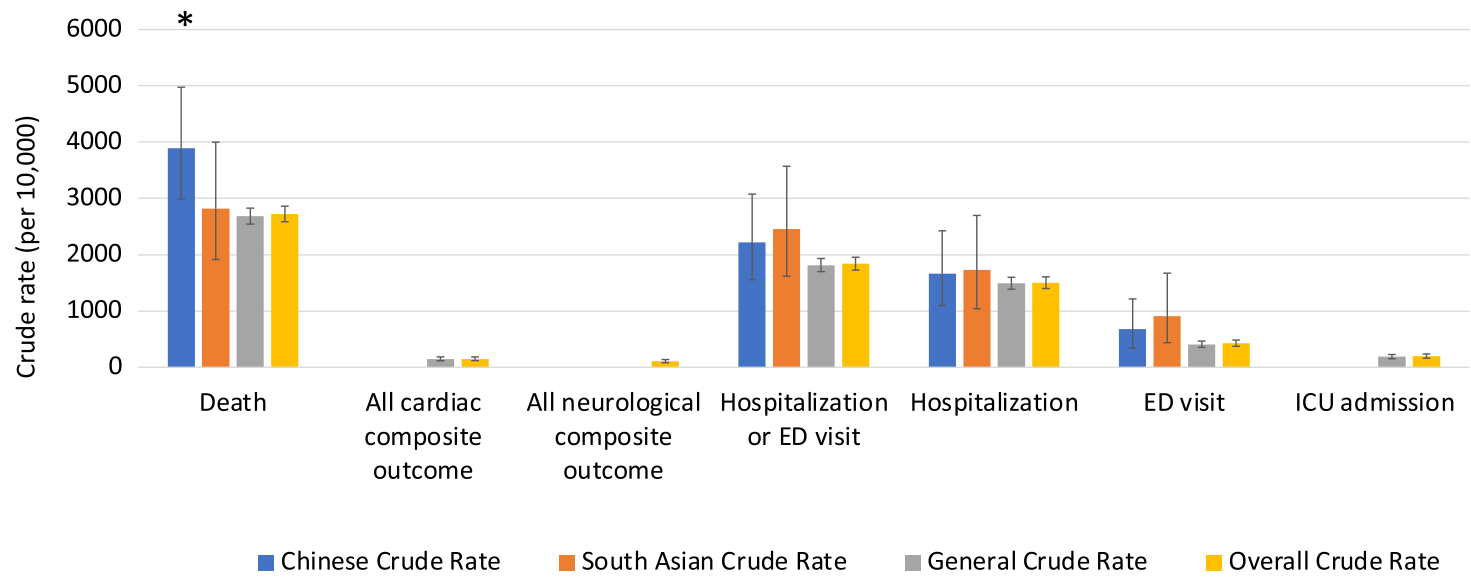

Figure 3: 30-day crude rates by ethnic groups for patients in long-term care. Data for patients who were in long-term care in the 90-day period before being tested positive for COVID-19. Error bars represent standard deviation. Asterisks indicate significant difference compared to the general crude rate. ED, emergency department; ICU, intensive care unit. 


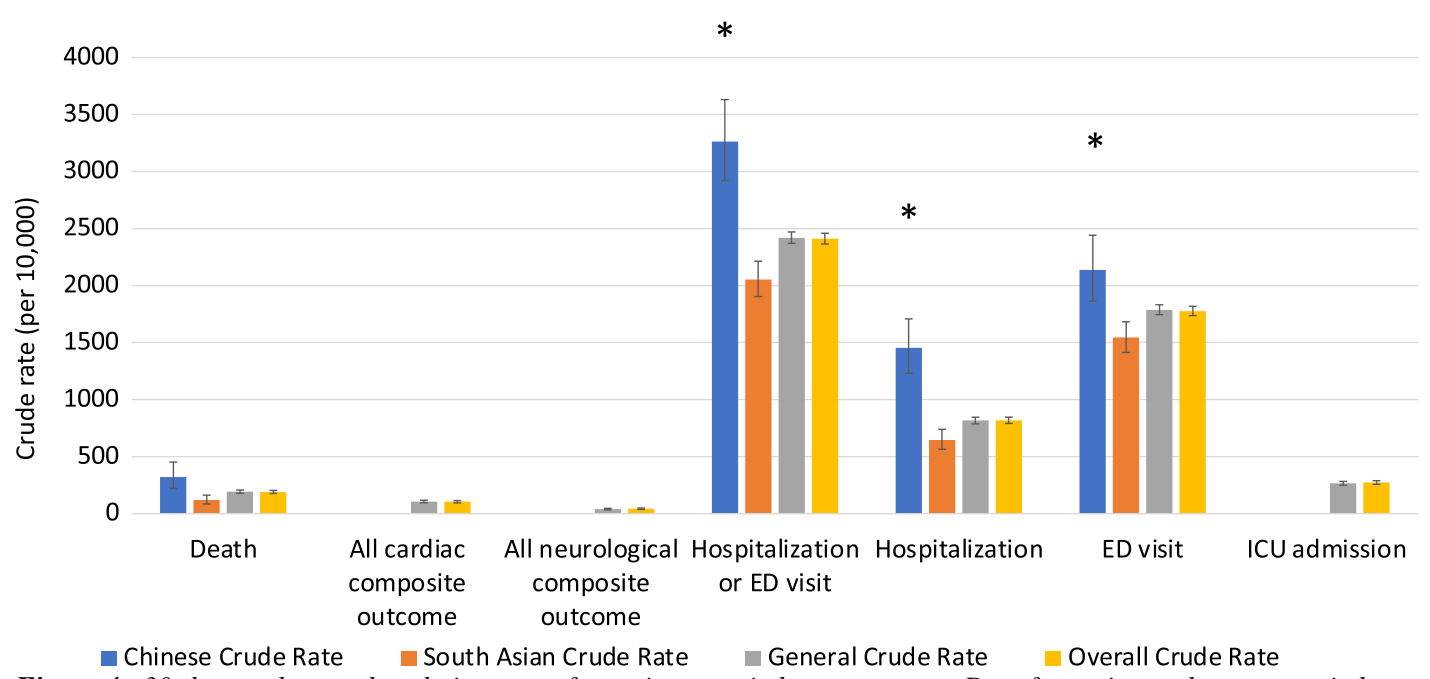

Figure 4: 30-day crude rates by ethnic groups for patients not in long-term care. Data for patients who were not in longterm care in the 90-day period before being tested positive for COVID-19. Error bars represent standard deviation. Asterisks indicate significant difference compared to the general crude rate. ED, emergency department; ICU, intensive care unit.

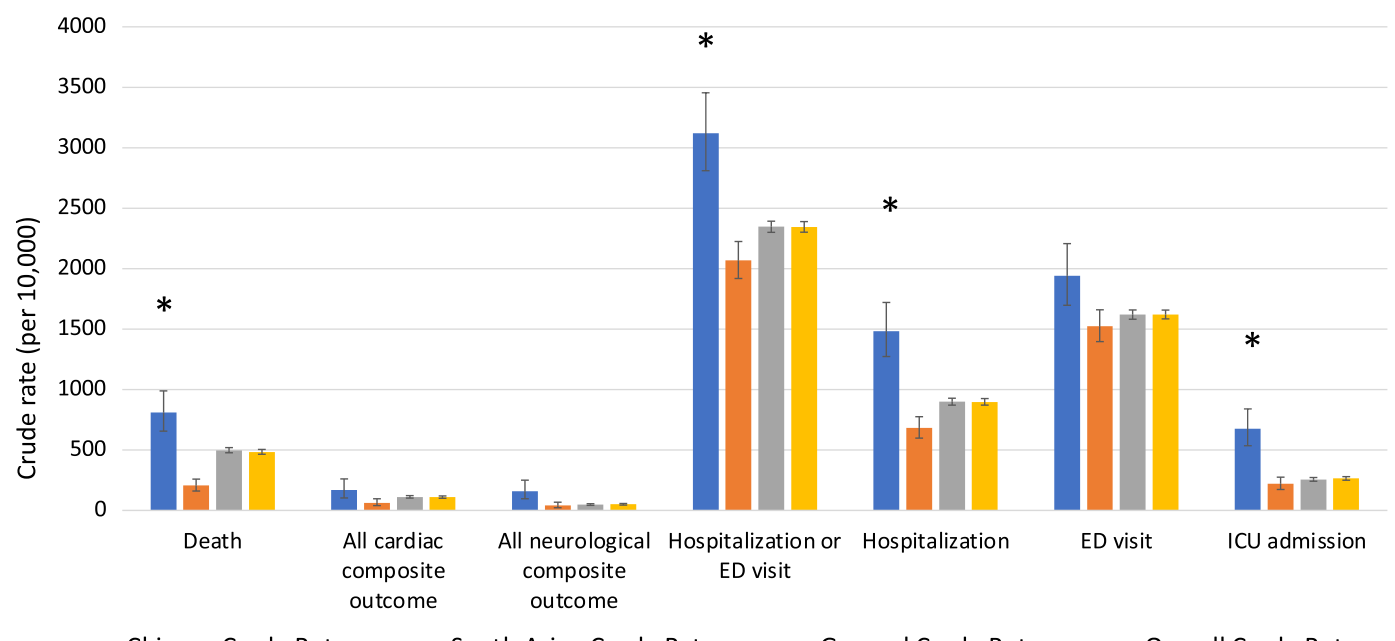

- Chinese Crude Rate $\quad$ South Asian Crude Rate General Crude Rate $\quad$ Overall Crude Rate

Figure 5: 30-day crude rates for by ethnic groups. Error bars represent standard deviation. Asterisks indicate significant difference compared to the general crude rate. ED, emergency department; ICU, intensive care unit.

long-term care facilities compared to $12.2 \%$ in the general population $(p<0.001)$, and their incidence of hospitalization during the past 5 years from index was lower at $18.1 \%$ compared to $25.8 \%$ in the general population $(p<0.001)$ (Table 2$)$. These differences could be due to the younger age of this cohort (Table 1). Their Charlson comorbidity index was significantly lower in incidence for heart failure, peripheral vascular disease, cerebrovascular disease, dementia, and COPD $(p<0.001)$ (Table 3$)$. Their overall mortality rate was much lower at $2.1 \%$ compared to the general population of $5.0 \%(p<0.001)$. The all cardiac complication rate was also lower at $0.6 \%$ vs $1.1 \%$ for the general population $(p<0.001)$, while the all neurological complication rate was similar to the general population $(0.4 \%$ vs $0.5 \%, p=0.526$ ). Although their hospitalization rate was lower, there were no difference in their ICU admission rate and mechanical ventilation rate when compared to the general population $(p>0.05)$ (Figure 5). The 30-day crude rate for cardiac complications among South Asians was 40/10,000 $(p=0.526)$ compared to the general population at $112 / 10,000$. The 30 -day crude rate for neurological complications among South Asians was $64 / 10,000(p=0.008)$ compared to the general population of 48/10,000 (Figure 5).

Multivariable logistic regression analysis demonstrated that ethnicity is a major determinant for 30 days overall mortality, cardiac, and neurological complications, hospitalization, or emergency department visits (Table 4). Chinese ethnicity, independent of their age, sex, income quintile, and long-term care placement within 90 days prior to positive COVID-19 tests were found to have higher ORs for all these outcomes, while they were lower in South Asians compared to the general population (Table 5). For Chinese, their mortality $\mathrm{OR}=1.743$; cardiac complications $\mathrm{OR}=1.433$; neurological complications $\mathrm{OR}=3.141$; and hospitalization or emergency department visits $\mathrm{OR}=1.437$. For South Asians, their mortality $\mathrm{OR}=0.981$; cardiac complications $\mathrm{OR}=0.707$; neurological complications $\mathrm{OR}=1.088$; and hospitalization or emergency department visits $\mathrm{OR}=0.869$. (Figure 6) 
Table 4: Absolute number of events by ethnic groups

\begin{tabular}{|c|c|c|c|c|}
\hline \multirow{2}{*}{ Outcomes } & Chinese & South Asian & General & Overall \\
\hline & $N=1,186$ & $\mathrm{~N}=\mathbf{3 , 4 5 9}$ & $\mathrm{N}=\mathbf{4 2 , 5 4 7}$ & $\mathrm{N}=47,192$ \\
\hline Death & $96(8.1 \%)$ & $71(2.1 \%)$ & $2,118(5.0 \%)$ & $2,285(4.8 \%)$ \\
\hline All cardiac composite outcome & $20(1.7 \%)$ & $22(0.6 \%)$ & $476(1.1 \%)$ & $518(1.1 \%)$ \\
\hline All neurological composite outcome & $19(1.6 \%)$ & $14(0.4 \%)$ & $205(0.5 \%)$ & $238(0.5 \%)$ \\
\hline Hospitalization or ED visits & $370(31.2 \%)$ & $715(20.7 \%)$ & $9,981(23.5 \%)$ & $11,066(23.4 \%)$ \\
\hline
\end{tabular}

ED = emergency department.

Table 5: Summary of odds ratios for death, cardiac complications, neurological complications, hospitalization, or emergency visits

\begin{tabular}{|c|c|c|c|}
\hline Comparison & Odds Ratio Estimate & Lower CL & Upper CL \\
\hline Death: Chinese vs General & 1.743 & 1.344 & 2.262 \\
\hline Death: South Asian vs General & 0.981 & 0.753 & 1.280 \\
\hline Cardiac: Chinese vs General & 1.433 & 0.903 & 2.274 \\
\hline Cardiac: South Asian vs General & 0.707 & 0.458 & 1.092 \\
\hline Neurological: Chinese vs General & 3.141 & 1.943 & 5.080 \\
\hline Neurological: South Asian vs General & 1.088 & 0.628 & 1.887 \\
\hline Hospitalization or ED: Chinese vs General & 1.437 & 1.263 & 1.635 \\
\hline Hospitalization or ED: South Asian vs General & 0.869 & 0.796 & 0.949 \\
\hline
\end{tabular}

$\mathrm{CL}=$ confidence limit, $\mathrm{ED}=$ Emergency department visit.

Odds ratios were obtained from logistic regression. Each ethic group was compared to the general population (General). Odds ratios that are significantly different from 1 are in bold.

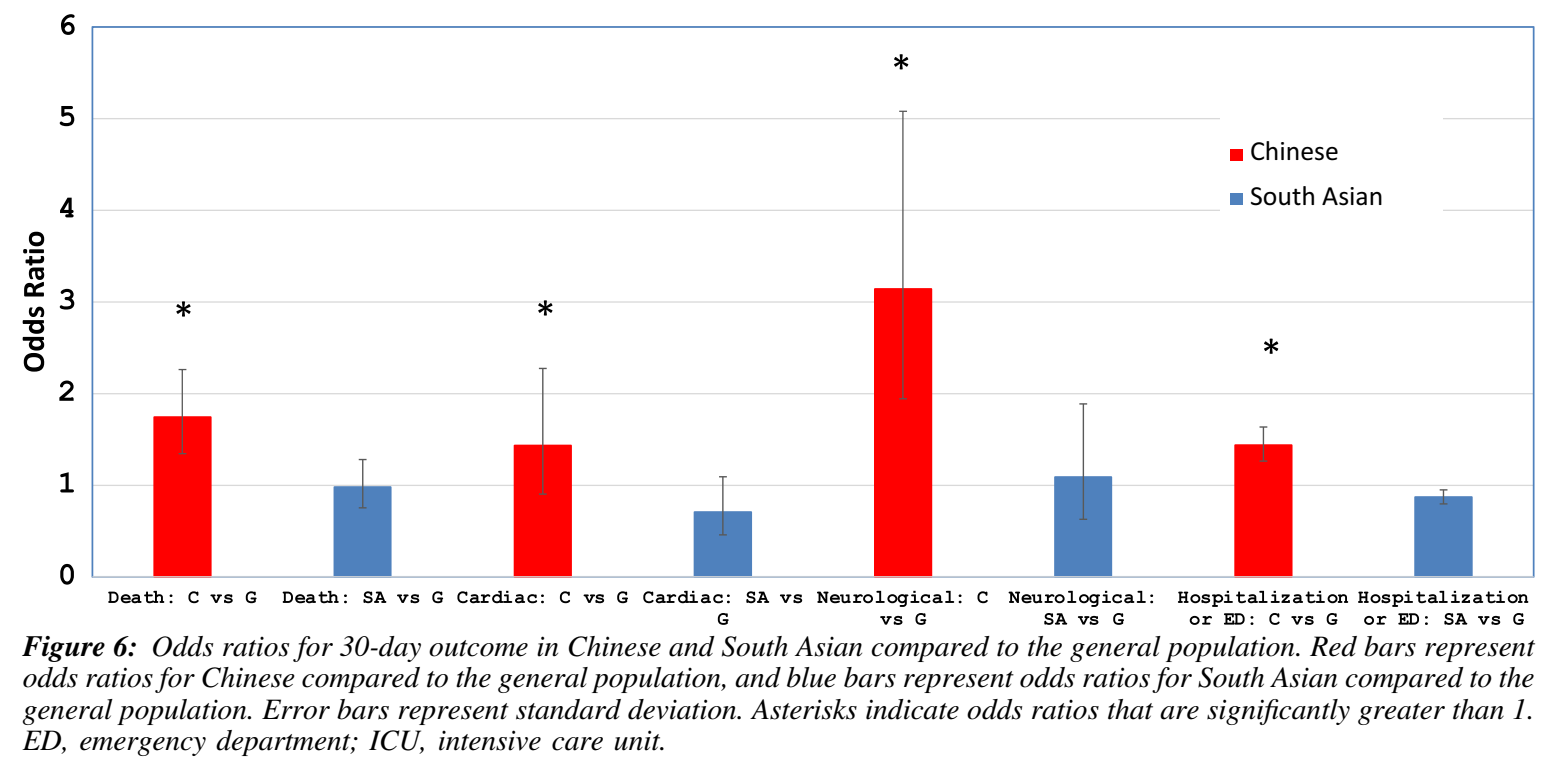

\section{DISCUSSION}

For Ontario visible minorities affected by COVID-19 during the first wave of the pandemic, Chinese were older, while South Asians were found to be relatively younger compared to the general population. This may be attributed in part to a much larger proportions of frontline health care workers and those in distribution centers are of South Asian descent and they have a lower socioeconomic status compared to the general population. ${ }^{2,10}$ This is further evidenced in our study indicating that only $8.2 \%$ of South Asians with COVID-19 was found to be in the highest income quintile 5, while Chinese and the general population were higher at $15.3 \%$ and $14.6 \%$, respectively (Table 1). 
Based on the 2016 Canadian census, ${ }^{42}$ Chinese accounts for $5.7 \%$ of Ontario population, while only $2.5 \%$ of this studied group was found to have COVID-19 and this is below the expected infection rate. This could be in part an under-estimation due to the sensitivity rate of $80.2 \%$ using the last name algorithm to identify Chinese. ${ }^{40}$ For South Asians, they account for $8.7 \%$ of the Ontario population and $7.3 \%$ was found to have COVID-19 which is very close to the expected infection rate. ${ }^{42}$ Chinese when tested positive for COVID-19 were more than likely to be at long-term care facilities compared to the general population (6.4\% vs $5.0 \%, p=0.031)$, while it was much lower for South Asians at $1.4 \%$ (Table 3$)$. History of heart failure $(p<0.004)$ and COPD $(p<0.003)$ were the only two baseline characteristics found to be less frequent for Chinese compared to the general population. Lower incidence of heart failure was also found among Chinese Americans in a previous study. ${ }^{51}$ The incidence of COPD was also found to vary by ethnicity in London, UK. ${ }^{53}$ Although there was no significant difference in the number of Charlson comorbidity index for Chinese, their hospitalization rates, emergency and ICU admission rates, cardiac and neurological complication rates, and overall mortality rates were much higher than the general population (Figure 5). Since many of these Chinese were residing in long-term care facilities, they were more vulnerable to be infected by COVID-19 and develop fatal complications. The overall mortality rates, hospitalization rates, ICU admission rates, and cardiac and neurological complication rates were all much higher among those 65 years or older in all three cohorts. This would indicate that age is a very important prognostication factor in patients infected with COVID-19, as reported previously. $6,15,16,26$

\section{Cardiac Complications}

One of the biggest risk factors for severe COVID-19 and fatality from COVID-19 is underlying cardiovascular (CV) disease comorbidity. ${ }^{27,40}$ However, in the current study, compared to the general population, the frequencies of $\mathrm{CV}$ disease comorbidity such as heart failure, COPD, and asthma in Chinese were significantly lower than in the general population, while in the South Asians, these conditions were less frequent except for asthma. We assessed for acute MI, heart failure, arrhythmia in general, atrial fibrillation and flutter, myocarditis, and DVT/PE. ${ }^{23}$ The incidence was too low in our study to draw conclusions regarding any potential differences between groups. The heart can be affected in diverse ways by COVID-19, ${ }^{31,34-38}$ and mechanisms of myocardial injury ${ }^{39}$ in patients with COVID19 include oxygen supply-demand imbalance, direct viral myocardial invasion, ${ }^{33}$ inflammation, coronary plaque rupture with acute MI, microvascular thrombosis, and adrenergic stress. ${ }^{32}$ The recent North American Cardiovascular COVID-19 Myocardial Infarction (NACMI) Registry ${ }^{48,49}$ that the primary outcome - a composite of in-hospital death, stroke, recurrent MI, or repeat unplanned revascularization - occurred in $36 \%$ of COVIDpositive patients, compared with $13 \%$ of COVID-negative patients and $5 \%$ of control subjects $(p<0.001$ relative to controls). This difference was driven largely by a high in-hospital death rate in COVID-positive patients. ST-segment elevation MI in COVID-positive patients disproportionately affects ethnic minorities (23\% Hispanic and 24\% Black) with diabetes, which was present in $46 \%$ of COVID-positive patients. Importantly,
$23 \%$ have no culprit vessel on angiography, and this may represent different etiologies of ST-segment elevation, including microemboli, myocarditis, ${ }^{33}$ and stress cardiomyopathy. It is noteworthy that Asians only comprised $6 \%$ of the study population and this underscores the importance of following the cause-specific outcomes in the Asian population.

\section{Neurological Complications}

Neurological complications of COVID-19 can be divided into two major categories: de novo neurological complications as a direct result of COVID-19 infections and exacerbation of preexisting neurological conditions when patients were infected by SARS-CoV-2 virus. ${ }^{7,9}$ In our current study, Chinese had no significant difference in the prevalence of pre-morbid conditions based on the Charlson comorbidity index compared to the general population. This would suggest that excessive neurological complication rate of Chinese could be due to a direct result of COVID-19 infection rather than exacerbation of their preexisting neurological conditions in addition to being older in their mean age. Among all the neurological complications, encephalopathy was the commonest accounting for $6.4 \%$ of hospitalized and $14.1 \%$ of Chinese patients admitted to ICU but it was not statistically significant compared to the general population. Encephalopathy in COVID-19 patients could be due to a combination of etiological factors: hypoxemia secondary to respiratory failure, toxic and metabolic factors secondary to acute illness and as well recently recognized inflammatory brain diseases. ${ }^{4,50}$ Encephalopathy of admitted COVID-19 patients in a large cohort study was associated with increased the risk of death by 5.5 times $(\mathrm{OR}=4.01-7.57, p<0.001) .{ }^{45}$ In our current study, there were very few cases of hemorrhagic ${ }^{11,21}$ and ischemic stroke, ${ }^{20,24,30}$ seizures and Parkinson's Disease among Chinese but this could be due to the relatively small number in this cohort. The estimated incidence of stroke as a complication of COVID-19 varies between $2.5 \%$ and $5 \%$ found in various recent publications. ${ }^{5,8}$ In addition, there were no cases reported with encephalitis, meningitis, Guillain-Barre syndrome, and inflammatory myositis in both the Chinese and South Asians. Ongoing pathological studies will be required to examine if there are direct invasion of the SARS-CoV-2 virus in neural tissues of the central and peripheral nervous system. ${ }^{4,12,47}$ These clinical-pathological studies would be vital in discovering if there are different pathophysiological mechanisms in explaining the difference in neurological complications between these 3 cohorts. $^{46}$ Although these are very rare neurological complications of COVID-19,,$^{3,4,15,22,25,45}$ we hope that with increasing number of patients in our future studies, the true incidence of these unusual neurological complications of COVID-19 among Chinese and South Asians in Ontario will be discovered.

\section{Limitations}

We used surname algorithm to classify surnames as Chinese, South Asian, or General. The data set excludes surnames which are not unique to one of these populations such as Khan, Ahmed, or Fernandes from the South Asian list, or Lee or Young from the Chinese list. As a result, the South Asian list includes predominantly Hindu surnames and is therefore most representative of Indian surnames; Muslim surnames from Pakistan and Bangladesh are often shared with Muslim populations from other 
world regions and are not included in the list. These exclusions resulted in an algorithm with a high specificity (99.7\% for both ethnicities) but lower sensitivity (50.4\% for South Asians, 80.2\% for Chinese). ${ }^{40}$ Another limitation is the surname algorithm cannot be used to identify Blacks and other visible minorities, and this study period covered mainly the first wave of COVID-19 in Ontario with limited data on ethnicity/race. Since we used only 30-day all-cause mortality rates, cardiac and neurological complication rates, the current study is not able to capture patients with "long-haul" COVID-19 symptoms ${ }^{7,12}$ even though they may have recovered from the acute illness. Another limitation relates to that hospital administrative records may not capture all complications and hence the true incidence of cardiac and neurological complications may be under-estimated in this study. ${ }^{45}$ We hope that with increasing number of patients in our future studies, the true incidence of these unusual neurological complications of COVID-19 among Chinese and South Asians in Ontario will be discovered.

\section{Conclusions}

In this preliminary cohort study, using multivariable logistic regression analysis, ethnicity was found to be the most important determinant for mortality, cardiac and neurological outcomes, and hospitalization rates for those Ontarians infected by COVID19 (Figure 6). These data have significant implications for health care policy-makers regarding resource allocation and vaccination priority $^{41}$ in order to provide proper prevention and appropriate medical care for those Chinese and South Asians who are residing in long-term care facilities. These elderly patients are more vulnerable to be infected by COVID-19 and develop fatal complications. For South Asians infected by COVID-19, even though they were relatively younger than the general population, their overall mortality rate was still of importance particular for those 65 years and older and for those residing in long-term facilities. In addition, these findings would be of importance to Ontario public health units and health care authorities when dealing with the second and third wave of this pandemic in Ontario.

\section{ACKNOWLEDGEMENTS}

This study was supported by the Ontario Health Data Platform (OHDP), a Province of Ontario initiative to support Ontario's ongoing response to COVID-19 and its related impacts. The opinions, results, and conclusions reported in this paper are those of the authors and are independent from the funding sources. No endorsement by the OHDP, its partners, or the Province of Ontario is intended or should be inferred. This study was supported by ICES, which is funded by an annual grant from the Ontario Ministry of Health (MOH) and the Ministry of LongTerm Care (MLTC). Parts of this material are based on data and/ or information compiled and provided by CIHI. However, the analyses, conclusions, opinions, and statements expressed in the material are those of the authors, and not necessarily those of CIHI.

\section{FUNDING}

Ontario Ministry of Health- Ontario Health Data Platform (OHDP); Project TRIM \# 20213155006 000-OHDP; Research
Fund-University of Toronto: Fund \# 472617/FC 100089/CC 10895; Research Committee, Chinese Canadian Heart and Brain Association (CCHABA)

\section{CONFLiCTS OF INTEREST}

None of the authors have any conflict of interests to declare for this study. Dr. Joseph Y. Chu is the Chair of Research of the Chinese Canadian Heart and Brain Association (CCHABA)

\section{Statement of Authorship}

Conception of study: Drs. JYC, GWM, and CC. Design of study: Drs. JYC, GWM, RC, DTK, and PPL; MK. Data collection and analysis: MK, YK. Writing of manuscript: Drs. JYC, GWM, and RC; MK and YK. Critical review of manuscript: Drs. JYC, GWM, RC, and DTK.

\section{SupPlementary Material}

To view supplementary material for this article, please visit https://doi.org/10.1017/cjn.2021.148.

\section{REFERENCES}

1. Public Health Ontario: COVID-19 in Ontario-A Focus on Diversity: January 15, to May 14, 2020.

2. Subedi R, Greenberg L, Turcotte M. Statistics Canada: StatCan COVID-19: COVID-19 mortality rates in Canada's ethno-cultural neighbourhoods, October 28, 2020.

3. Nepal G, Rehrig JH, Shretha GS, et al. Neurological manifestations of COVID-19: a systematic review. Critical Care. 2020;24:421.

4. Ellul MA, Benjamin L, Singh B, et al. Neurological associations of COVID-19. Lancet Neurol. 2020;19:767-83.

5. Frontera JA, Sabadia S, Lalchan R. A prospective study of neurologic disorders in hospitalized patients with COVID-19 in New York City: Neurology. 2021;96:e575-86.

6. O'Brien K, St-Jean M, Wood P, et al. StatCan COVID-19 death comorbidities in Canada, November 16, 2020.

7. Narth A. Neurologic complications of coronavirus infections. Neurology. 2020;94:809-10.

8. Wang L, Shen Y, Li M, et al. Clinical manifestations and evidence of neurological involvement in 2019 novel coronavirus SARSCoV-2: a systematic review and meta-analysis. J Neurol. 2020;267:2777-89.

9. Niazkar HR, Zibaee B, Nasimi A, et al. The neurological manifestations of COVID-19: a review article. Neurol Sci. 2020;41: 1667-71.

10. StatCan: Impacts on Immigrants and People Designated as Visible Minorities, October 20, 2020.

11. Dhamoon MS, Thaler A, Gururangan K, et al. Acute cerebrovascular events with COVID-19 infection. Stroke. 2021;52:48-56.

12. Troxel AB, Frontera JA, Mendoza-Puccini C. The National Institutes of Health COVID-19 NeuroDatabank and NeuroBiobank: A National Resource for Learning, Discovery, and Progress. Front Neurol. 2021;11:615061.

13. CDC: COVID-19 in Racial and Ethnic Minority Groups, June 4, 2020.

14. Suleyman G, Fadel RA, Malette K, et al. Clinical characteristics and morbidity associated with Coronavirus disease 2019 in a series of patients in Metropolitan Detroit. JAMA Netw Open. 2020;3: e2012270.

15. Wang D, Yin $\mathrm{Y}, \mathrm{Hu} \mathrm{C}$, et al. Clinical course and outcome of 107 patients infected with the novel Coronavirus, SARS-CoV-2, discharged from two hospitals in Wuhan, China. Crit Care. 2020;24:188.

16. Hooper MW, Napoles AM, Perez-Stable EJ. COVID-19 and racial/ ethnic disparities. JAMA. 2020;323:2466-7. 
17. APM Research Lab. The Color of Coronavirus: COVID-19 Deaths by Race and Ethnicity in the U.S. May 12, 2020.

18. Haynes N, Cooper LA, Albert MA. At the heart of the matter: unmasking and addressing COVID-19's toll on diverse populations. Circulation. 2020;142:105-7.

19. Laurencin C, McClinton A. The COVID-19 pandemic: a call to action to identify and address racial and ethnic disparities. J Racial and Ethnic Health Disparities. 2020;7:398-402.

20. Van der Worp B, Sandset EC, Caso V. Likely Increase in the Risk of Death or Disability from Stroke during the COVID-19 Pandemic, European Stroke Organization, May 9, 2020.

21. Oxley TJ, Mocco J, Majidi S, et al. Large-Vessel Stroke as a Presenting Feature of COVID-19 in the Young. N Engl J Med. 2020;382:e60.

22. Tu H, Tu S, Gao S, et al. The epidemiological and clinical features of COVID-19 and lessons from this global infectious public health event. J Infecti. 2020;81:1-9.

23. Lodigiani C, Iapichino G, Carenzo L, et al. Venous and arterial thromboembolic complications in COVID-19 patients admitted to an academic hospital in Milan, Italy. Thromb Res. 2020;191: 9-14.

24. Qureshi A, Abd-Allah F, Alsenani F, et al. Management of acute ischemic stroke in patients with COVID-19 infection: Report of an international panel. Int J Stroke. 2020;15:540-54.

25. Zhou, Y, Li W, Wang D, et al. Clinical time course of COVID-19, its neurological manifestation and some thoughts on its management. Stroke Vasc Neurol. 2020;5:177-9.

26. Guo T, Fan Y, Chen M, et al. Cardiovascular implications of fatal outcomes of patients with coronavirus disease 2019 (COVID-19). JAMA Cardiol. 2020;5:811-8.

27. Shi S, Qin M, Shen B, et al. Association of cardiac injury with mortality in hospitalized patients with COVID-19 in Wuhan, China. JAMA Cardiol. 2020;5:802-10.

28. DataSF. Demographics of COVID-19 Cases and Deaths, City and Country of San Francisco.

29. Warrior L, Kim CY, Burdick DJ, et al. Leading with inclusion during the COVID-19 pandemic. Neurology. 2020;95:537-42.

30. Khosravani H, Rajendram P, Notario L, et al. Protected code stroke: hyperacute stroke management during the coronavirus disease 2019 (COVID-19) pandemic. Stroke. 2020;51: 1891-5.

31. Canadian Cardiovascular Society. Guidance from the CCS COVID19 rapid response team: is it COVID-19 or is it heart failure? Management of ambulatory heart failure patients.

32. Giustino G, Pinney S, Lala A, et al. Coronavirus and cardiovascular disease, myocardial injury, and arrhythmia. Focus Seminar. J Am Coll Cardiol. 2020;76:2011-23.

33. Kawakami R, Sakamoto A, Kawai K, et al. Pathological evidence for SARS-CoV-2 as a cause of myocarditis. JACC review topic of the week. J Am Coll Cardiol. 2021;77:314-25.

34. Panjrath G, Krepp J. COVID-19 and heart failure: harsh reality of pre-existing conditions. J Am Coll Cardiol. 2020;76:2349-51.
35. Alvarez-Garcia J, Lee S, Gupta A, et al. Prognostic impact of prior heart failure in patients hospitalized with COVID-19. J Am Coll Cardiol. 2020;76:2334-48.

36. Mehra MR, Ruschitzka F. COVID-19 illness and heart failure: a missing link? JACC Heart Fail. 2020;8:512-4.

37. Bhatt AS, Jering KS, Vaduganathan M, et al. Clinical outcomes in patients with heart failure hospitalized with COVID-19. JACC Heart Fail. 2021;9:65-73.

38. Freaney PM, Shah SJ, Khan SS. COVID-19 and heart failure with preserved ejection fraction. JAMA. 2020;324:1499-500.

39. Tersalvi G, Vicenzi M, Calabretta D, et al. Elevated troponin in patients with Coronavirus Disease 2019 (COVID-19): possible mechanisms. J Card Fail. 2020;26:470-5.

40. Shah BR, Chiu M, Amin S, Ramani M, Sadry S, Tu JV. Surname lists to identify South Asian and Chinese ethnicity from secondary data in Ontario, Canada: a validation study. BMC Med Res Methodol. 2010;10:42. doi: 10.1186/1471-2288-10-42

41. Wang C, Wang Z, Wang G, Lau JY-N, Zhang K, Li W. COVID-19 in early 2021: current status and looking forward. Signal Transduct Target Ther. 2021;6:114.

42. StatCan Census Profile 2016: Ontario (Province) and Canada. https//: www12.stacan.gc.ca

43. Needham EJ, Chou SH-Y, Coles AJ, Menon DK. Neurological implications of COVID-19 infections. Neurocrit Care. 2020;32:667-71. doi: 10.1007/s12028-020-00978-4

44. Mao, L, Wang M, Chen S, et al. Neurological manifestations of hospitalized patients with COVID-19in Wuhan, China: a retrospective case series study. medRxiv. 2020. doi: 10.1101/2020.02. 22.20026500

45. Chou S. AAN-2021 conference: hot topics: neuro-COVID plenary session. Neurol Complicat COVID-19. 2021.

46. Vinciguerra M, Greco E. Sras-CoV-2 and black population: ACE2 as shield or blade? Infect Genet Evol. 2020;84:104361.

47. Normandin E, Bhattacharyya S, Mukerji S, et al. Neuropathological features of COVID-19. https://index.mirasmart.com/AAN2021/ PDFfiles/AAN2021-004641.html.

48. Kornowski R, Orvin K. The Clinical Challenge of ST-Segment Elevation Myocardial Infarction and COVID-19. J Am Coll Cardiol. 2021;77:2004-6.

49. Garcia S, Dehghani P, Grines C, et al. Initial Findings From the North American COVID-19 Myocardial Infarction Registry. J Am Coll Cardiol. 2021;77:1994-2003.

50. Remsik J, Wilcox JA, Babady NE, et al. Inflammatory leptomeningeal cytokines mediate COVID-19 neurological symptoms in cancer patients. Cancer Cell. 2021;39:276-83.

51. Bahrami H, Kronmal R, Bluemke DA, et al. Differences in the incidence of congestive heart failure by ethnicity: the multi-ethnic study of atherosclerosis. Arch Intern Med. 2008;168:2138-45. doi: 10.1001/archinte.168.19.2138

52. Gilkes A, Ashworth M, Schofield P, et al. Does COPD risk vary by ethnicity? A retrospective cross-sectional study. Int J COPD. 2016;11:739-46. 